\title{
Drogadicción y Delincuencia. Perspectiva desde una prisión.
}

\author{
Juan José Santamaría Herrero*; leila Chait** \\ *Psicólogo por la Universidad de Granada, Master en Drogodependencias. \\ * Psicóloga por la Universidad Autónoma de Barcelona y por la de Buenos Aires, Master en Drogodependencias. \\ Centro Penitenciario Madrid II (Alcala-Meco).
}

Enviar correspondencia a:

Juan José Santamaría Herrero. C Catalanes n², 6º. 18600 MOTRIL (Granada). Telefono: 646212529. Correo electrónico: psicojule@yahoo.es

Recibido: 11 de diciembre de 2003.

Aceptado: 22 de junio de 2004.

\section{RESUMEN}

El objetivo de realizar esta investigación ha sido conocer, estudiar y describir tanto la relación que existe entre drogadicción y delincuencia, como analizar en qué estado, bajo los efectos de qué sustancias y qué tipos de delitos cometen los sujetos drogodelincuentes.

Con tal objetivo, se realizó un estudio descriptivo de corte transversal con una muestra de 88 drogodependientes reclusos del Centro Penitenciario Madrid II. Posteriormente analizada con el paquete estadístico SPSS.

Los principales resultados muestran que una gran proporción de reclusos combinan heroína y cocaína, independientemente del estado en el que realizan el delito y que la droga por la que más delinquen es la cocaína.

Las conclusiones más importantes reflejan que la mayoría de los sujetos estudiados cometieron el delito por el que actualmente están presos en estado de intoxicación y que en la mayoría de los drogodelincuentes existen factores comunes en la génesis de ambas entidades, desmintiendo la creencia de que la drogadicción lleva a la delincuencia.

Palabras clave: Drogadicción, delincuencia, prisión.

\section{ABSTRACT}

The objective of this research was twofold; to ascertain, study and describe both the relationship between drug addition and criminality, and to analyse the state of drug criminal subjects, the substances that were effecting them and the types of crime they committed.

For that purpose, a descriptive cross-study was carried out on a sample of 88 drug-addicts, imprisoned in the Madrid II gaol, being subsequently analysed with the SPSS statistical pack.

The main results show that a high proportion of recluses combine heroine and cocaine, irrespective of the state in which they committed the crime, and that the most commonly used drug when a crime is committed is cocaine.

The main conclusions point to the majority of the subjects of the study committing the crime for which they now imprisoned in a state of intoxication, and that in most drug addicts, there are common factors in the genesis of both criminality and drug addiction, thereby disproving the belief that drug-addiction leads to criminality.

Key words: Drug addition, criminality, prison.

\section{INTRODUCCIÓN}

C on el presente trabajo se pretende analizar la relación que existe entre la delincuencia y la drogadicción.

Revisando la literatura científica, dos grandes bloques han guiado las investigaciones hasta ahora realizadas:

Por un lado investigaciones dirigidas a conocer la capacidad criminógena de las distintas sustancias psicoactivas, y por otro lado el conocer qué conduce a qué; si la drogadicción lleva a la delincuencia; si es la delincuencia lo que lleva a la drogadicción o si existen factores comunes a ambas entidades. Según los resultados encontrados en investigaciones como por ejemplo la de Marquez Cervilla (1990), los sujetos que son a la vez delincuentes y drogadictos están implicados con anterioridad en la delincuencia que en la drogadicción.

La motivación para realizar esta investigación surgió de la intención de comprobar como afecta al binomio droga - delincuencia el cambio que se está produciendo en la sociedad en cuanto a los tipos y formas de consumos. 
En el tema de las adicciones se está viendo en la sociedad dos hechos importantes: por un lado la población heroinómana se mantiene estable, no aumenta, el grupo de estos sujetos es el mismo desde hace años. Y por otro, está aumentando el número de sujetos con problemas de consumos de cocaína. En la práctica clínica comienza a observarse por primera vez, que el número de sujetos cocainómanos en primera atención, supera al de heroinómanos. (dato que se confirma en el informe $n^{\circ} 5$ del observatorio español sobre drogas, en el indicador "sujetos atendidos por primera vez a tratamiento").

El objetivo de realizar esta investigación ha sido conocer, estudiar y describir tanto la relación que existe entre drogadicción y delincuencia, como analizar en qué estado, bajo los efectos de qué sustancias y qué tipos de delitos cometen los sujetos drogodelincuentes.

\section{MATERIAL Y METODOS}

Se realizó un estudio descriptivo de corte trasversal con 123 varones reclusos del centro penitenciario Madrid II entre enero y octubre del 2003.

Las dos características buscadas en los sujetos participantes de la investigación fueron: ser delincuentes y ser drogadictos.

Para la primera característica, ser delincuente, seleccionamos, una muestra de sujetos internos del Centro Penitenciario Madrid II 1 .

La segunda característica que tenia que tener la muestra, era el que esos sujetos que estaban en prisión, fuesen drogadictos. Dicha característica se obtuvo a priori, de los sujetos que estaban incluidos en los distintos programas de tratamiento de drogodependientes.

El siguiente paso fue realizar entrevistas individuales a esa muestra seleccionada, con el fin de descartar a sujetos que no cumpliesen con la definición de las variables (que a continuación se explican) y controlar lo mejor posible la muestra con la que realizar este estudio. A continuación se elaboró un cuestionario con el que analizar a esta población.

Los internos fueron informados previamente del objetivo de la entrevista y accedieron a su realización de forma voluntaria.

\section{Definición Variables}

\section{Delincuente}

Tras la entrevista, se incluyó en la muestra sólo a sujetos que les hubiesen detenido en 3 ó más actos delictivos, (hubiesen o no entrado en prisión por ellos), ya que un "delincuente" es una persona con una carrera delictiva y no una persona con un solo acto delictivo y que además haya tenido ya algún contacto previo con la justicia. (Marquez Cervilla A, 1990; Garrido $V$ y otros, 1999).

Cuatro de los sujetos inicialmente entrevistados, no cumplían con este criterio, por lo cual fueron excluidos de la investigación, quedando un total de 119 sujetos.

Se analizaron los siguientes delitos:

Homicidio y sus formas ${ }^{2}$

Delito contra la salud publica ${ }^{3}$

Robo con fuerza ${ }^{4}$

Robo con intimidación ${ }^{5}$

Delito de Lesiones ${ }^{6}$

Atentado a la autoridad ${ }^{7}$

Delitos contra la libertad; detenciones ilegales y secuestros $^{8}$

Estos, se eligieron por ser los delitos representativos de la muestra (información obtenida en las entrevistas previas).

Así mismo se excluyeron los sujetos que habían realizado exclusivamente cierto tipos de delitos como infracciones contra la seguridad del tráfico, impago de multas. Restando a la muestra inicial 3 sujetos, quedando un total de 116 sujetos. Reseñar que en el análisis final no se ha tenido en cuenta el pequeño tráfico de drogas que se realiza con el fin exclusivo de comprar drogas. (la figura del receptador, recogida en el Titulo XIII Capítulo XIV del vigente código penal).

\footnotetext{
${ }^{1}$ Centro Penitenciario de hombres

${ }^{2}$ Título I del vigente código penal

${ }^{3}$ Título XVII Capitulo III del vigente código penal

${ }^{4}$ Título XIII Capitulo II Art. 238 y siguientes

${ }_{5}^{5}$ Título XIII Capitulo II Art. 242 del vigente código penal

${ }^{6}$ Título III del vigente Código penal

${ }^{7}$ Título XXII Capítulo II del vigente Código Penal

${ }^{8}$ Título VI Capitulo I del vigente Código Penal
} 


\section{Drogadicción}

Se objetivó esta variable siguiendo los criterios del DSM IV (tolerancia, abstinencia, uso compulsivo, deterioro biopsicosocial, etc).

También fueron excluidos del estudio, aquellos sujetos que estaban incluidos en programas de drogodependencias pero que no tenían ninguna dependencia a sustancias, como mucho han sido o son consumidores ocasionales de drogas. La mayoría de ellos son traficantes que han declarado ser drogodependientes para que se les tuviese en cuenta como atenuante en el juicio. También hay internos que aún no habiendo declarado en el momento del juicio ser drogadictos, se acercan o están en programas para drogodependientes pensado que van a tener algún tipo de beneficio penitenciario. Debido a este criterio, fueron apartados de la muestra inicial 28 sujetos más.

Finalmente, quedaron seleccionados 88 individuos que cumplían los criterios establecidos anteriormente y se procedió a pasarles un cuestionario de elaboración propia de manera individual y reiterando nuevamente el carácter confidencial de los datos que se recogían y la voluntariedad del mismo: Perfil Drogodependencia - Delincuencia9.

Dicho cuestionario está compuesto por preguntas que exploran: cuestiones sociodemográficas, ambiente familiar, drogadicción y delincuencia.

Una vez terminada la recogida de datos se procedió a analizar los resultados con el paquete estadístico SPSS 9.0.1

\section{MEDICIONESY RESULTADOS PRINCIPALES}

Para la descripción de la muestra se han realizado análisis de frecuencias y tablas de contingencia. También se ha utilizado el coeficiente de correlación de Spearman para el estudio de relación entre variables. Los datos fueron codificados en el paquete estadístico SPSS versión 9.0.1 y posteriormente, se ha realizado el análisis e interpretación de los resultados obtenidos.

\section{Análisis descriptivo de resultados.}

En cuanto a los datos sociodemográficos (Tabla1):
TABLA 1: Datos Sociodemográficos

\begin{tabular}{|c|c|}
\hline EDAD MEDIA & 31,83 años \\
\hline \multicolumn{2}{|l|}{ NACIONALIDAD } \\
\hline Español & $95,5 \%$ \\
\hline Extranjero & $4,5 \%$ \\
\hline \multicolumn{2}{|l|}{ ESTADO CIVIL } \\
\hline Soltero & $55,7 \%$ \\
\hline Casado & $9,1 \%$ \\
\hline Pareja de hecho o vivir en pareja & $19,3 \%$ \\
\hline Separado & $11,4 \%$ \\
\hline Divorciado & $3,4 \%$ \\
\hline Viudo & $1,1 \%$ \\
\hline \multicolumn{2}{|l|}{ No HIJOS } \\
\hline 0 & $46,6 \%$ \\
\hline 1 & $37,5 \%$ \\
\hline 2 & $6,8 \%$ \\
\hline 3 & $4,5 \%$ \\
\hline 4 & $3,4 \%$ \\
\hline 5 & $1,1 \%$ \\
\hline \multicolumn{2}{|l|}{ NIVEL ESTUDIOS ALCANZADO } \\
\hline No sabe leer ni escribir & $2,3 \%$ \\
\hline Sin estudios- Leer y escribir & $8 \%$ \\
\hline Primarios & $44,3 \%$ \\
\hline Graduado Escolar & $42 \%$ \\
\hline BUP / F.P. & $3,4 \%$ \\
\hline \multicolumn{2}{|l|}{ TRATAMIENTOS ANTERIORES DE } \\
\hline \multicolumn{2}{|l|}{ DROGODEPENDENCIAS } \\
\hline Si & $67 \%$ \\
\hline No & $33 \%$ \\
\hline \multicolumn{2}{|l|}{ TRATAMIENTO ACTUAL } \\
\hline P.L.D. & $46,6 \%$ \\
\hline Naltrexona & $1,1 \%$ \\
\hline P.M.M. & $52,3 \%$ \\
\hline \multicolumn{2}{|l|}{ ENFERMEDADES ASOCIADAS AL } \\
\hline CONSUMO & $59,1 \%$ \\
\hline VIH & $27,3 \%$ \\
\hline HEPATITIS B & $31,8 \%$ \\
\hline HEPATITIS C & $40,9 \%$ \\
\hline TUBERCULOSIS & $6,8 \%$ \\
\hline
\end{tabular}

El total de la muestra fue integrado por varones siendo su edad media de 31,83 años, siendo el 95,5\% de nacionalidad española.

El 55,7\% declara estar soltero y el 53,4\% tener uno ó mas hijos.

\footnotetext{
${ }^{9}$ Elaborado por: Yolanda Cagigal Méndez y Juan José Santamaría Herrero
} 
En cuanto al nivel de estudios alcanzado el 44,3\% manifestó tener estudios primarios y el $42 \%$ el graduado escolar, cabe destacar que muchos de los que poseen el título de graduado escolar se han sacado dicho titulo en su estancia en prisión.

El $67 \%$ de los entrevistados había estado anteriormente en tratamiento. En esta pregunta se tuvo que aclarar a más de un sujeto que no se entiende como "tratamiento" haber estado encerrado en su casa automedicándose.

En prisión básicamente hay 3 tipos distintos de tratamiento: Programa libre de drogas (P.L.D.); Programa de tratamiento de deshabituación con antagonistas opiáceos (Naltrexona) y Programa de mantenimiento con Metadona (P.M.M.).

De los sujetos entrevistados 46 (el 52,3\% de la muestra) están en P.M.M.. 41 (el 46,6\% de la muestra) están en PLD y un sujeto (que representa el 1,1\% de la muestra) está en Naltrexona.

El $59,1 \%$ padecen o han padecido alguna enfermedad asociada al consumo: El 27,3\% VIH; un 31,8\% Hepatitis B; un 40,9\% Hepatitis C y un 6,8\% tuberculosis.

Cuatro preguntas del cuestionario exploran el ambiente familiar (Tabla 2):

TABLA 2: Datos Ambiente Familiar

FAMILIARES PROBLEMAS CONSUMO $\quad 45,5 \%$

CONSUMO FAMILIAR ANTERIOR A SUS

CONSUMOS

$39,8 \%$

SITUACIÓN ACTUAL DE PRISIÓN DE

ALGÚN FAMILIAR

$28,4 \%$

PRISIÓN DE ALGÚN FAMILIAR

ANTERIOR A SU PRIMER INGRESO 43,2\%

El $45,5 \%$ tiene o ha tenido familiares con problemas de consumo. El 39,8\% veía consumir a alguien de su familia antes de consumir él (consumo de drogas ilegales y consumo problemático de alcohol).

El $28,4 \%$ tiene o a tenido alguna vez un familiar en prisión durante su propia estancia en el centro y un $43,2 \%$ ha tenido un familiar en prisión antes de entrar él.

Los datos recogidos en torno a Drogadicción y Delincuencia (TABLA 3)
TABLA 3: Frecuencias Referidas a preguntas sobre Drogadicción Y Delincuencia

\begin{tabular}{ll}
\hline EDAD MEDIA INICIO CONSUMO & 14,14 años \\
\hline $\begin{array}{l}\text { EDAD MEDIA INICIO } \\
\text { DROGADICCIÓN }\end{array}$ & 18,07 años \\
\hline $\begin{array}{l}\text { EDAD MEDIA COMISIÓN } \\
\text { PRIMER DELITO }\end{array}$ & $16,24 a n ̃ o s$ \\
\hline
\end{tabular}

EDAD MEDIA INICIO CARRERA

DELICTIVA

17,47 años

\section{DIRECCIONALIDAD}

Carrera Delictiva $\rightarrow$ Drogadicción $\quad 13,6 \%$

Drogadicción $\rightarrow$ Carrera Delictiva $\quad 33 \%$

Factores Comunes $\quad 53,4 \%$

\section{ESTADO DURANTE LA COMISION}

DEL DELITO

Intoxicado

$53,4 \%$

Síndrome Abstinencia

$29,5 \%$

Sobrio

$17 \%$

\section{COMISION DELITOS PARA \\ CONSEGUIR DROGA}

$88,6 \%$

MEDIA N DELITOS EN QUETE

HAN DETENIDO

$13,52 \%$

\section{AUMENTO DELITOS CON}

DEPENDENCIA

$88,6 \%$

\section{MEDIA N ${ }^{\circ}$ INGRESOS EN CENTRO}

CERRADO

$4,85 \%$

\section{EDAD PRIMER INGRESO CENTRO \\ CERRADO}

Menos de18 años

$34,1 \%$

18 - 21 años

$30,7 \%$

$21-25$ años

25 - 30 años

$12,5 \%$

Más de 30 años

$14,8 \%$

\section{CAUSAS PENDIENTES} $38,6 \%$

TIEMPO CONSUMO ANTES INCIAR

\section{TRATAMIENTO}

Menos de 3 años

$3-6$ años

$29,5 \%$

6 - 9 años

$18,2 \%$

Mas de 9 años

La edad media de inicio de consumo, sea cual sea el tipo de droga, se situó en los 14,14 años y la edad media en la que tenían un problema de drogadicción en los 18,07 años (se les explicó de diferentes formas lo que es tener una dependencia con la intención de unificar el significado del termino).

La edad media de comisión del primer delito se sitúa en los 16,24 años. Y la edad media en la que comenzó su carrera delictiva es de 17,47 años. 
En el 13,6\% de la muestra fue su carrera delictiva lo que le llevó a la drogadicción; al 33\% la drogadicción le llevó a una carrera delictiva; y para el 53,4\% existieron una serie de factores comunes, de manera que los sujetos expuestos a esos factores pudieron desarrollar las dos conductas indistintamente o conjuntamente.

A la hora de analizar la delincuencia, se les preguntó por el estado en el que realizaron el/los delito/s que están cumpliendo actualmente y las diferentes respuestas fueron:

El 53,4\% lo realizó en estado de intoxicación, un $29,5 \%$ con el síndrome de abstinencia y un $17 \%$ sin estar bajos los efectos de ningún tipo de sustancia. Es decir, en el 82,9\% de los casos analizados la droga estuvo por medio en la comisión del acto delictivo que están cumpliendo actualmente.

El 88,6\% (78 individuos) declaró haber delinquido en alguna ocasión para conseguir dinero para poder comprar droga:

- 74 (de los 78) manifestaron haber delinquido para comprar Cocaína (el 94,87\%).

- 64 (de los 78) manifestaron haber delinquido para comprar Heroína (el 82,05\%).

- 61 (de los 78) manifestaron haber delinquido para comprar cocaína y heroína (el 78,2\%).

La media del número de delitos en los que les han detenido (hayan o no ingresado en prisión) fue de 13,52 .
El 88,6\% manifestó que aumentó el número de delitos cuando ya tenían una dependencia.

La media de ingresos en centro cerrado (tanto prisión como reformatorio) es de 4,85 ingresos por persona. El 65,9\% de la muestra había ingresado antes de los 21 años en un centro cerrado.

El 61,4\% no tenían (hasta el momento en el que se realizó la encuesta) causas pendientes.

El 80,7\% estuvo más de 3 años con un problema de consumo antes de iniciar un tratamiento.

En la siguiente tabla se pueden contemplar los principales delitos por los que están actualmente en prisión (Tabla 4):

\section{TABLA 4: Principales delitos cometidos}

$\begin{array}{lc}\text { HOMICIDOY SUS FORMAS } & 10,1 \% \\ \text { DELITO CONTRA LA SALUD PUBLICA } & 5,7 \% \\ \text { ROBO CON FUERZA } & 27,3 \% \\ \text { ROBO CON INTIMIDACIÓN } & 67 \% \\ \text { DELITOS CONTRA LA LIBERTAD } & 5,7 \%\end{array}$

\section{Correlación entre variables}

Se utilizó el coeficiente de correlación de Spearman, estudiándose la relación entre los siguientes pares de variables (Tabla 5):

\begin{tabular}{|c|c|c|c|}
\hline \multicolumn{4}{|c|}{ TABLA 5: Correlaciones estudiadas } \\
\hline VARIABLE 1 & VARIABLE 2 & $\begin{array}{c}\text { COEF. DE } \\
\text { CORRELACION } \\
\text { DE SPEARMAN }\end{array}$ & SIGNIFICANCIA \\
\hline $\begin{array}{l}\text { Haber consumido Cocaína al } \\
\text { realizar el delito }\end{array}$ & $\begin{array}{l}\text { Haber consumido Heroína al } \\
\text { realizar el delito }\end{array}$ & 0,391 & $0,000 * *$ \\
\hline Delinquir intoxicado & $\begin{array}{l}\text { Haber consumido Cocaína al } \\
\text { realizar el delito }\end{array}$ & 0,383 & $0,000 * *$ \\
\hline Delinquir intoxicado & $\begin{array}{l}\text { Haber consumido Alcohol al } \\
\text { realizar el delito }\end{array}$ & 0,363 & $0,001 * *$ \\
\hline Delinquir intoxicado & $\begin{array}{l}\text { Haber consumido Benzodiacepinas } \\
\text { al realizar el delito }\end{array}$ & 0,355 & $0,001 * *$ \\
\hline Delinquir intoxicado & Delito de lesiones & 0,260 & $0,014 *$ \\
\hline $\begin{array}{l}\text { Haber consumido Alcohol al } \\
\text { realizar el delito }\end{array}$ & Delito de lesiones & 0,237 & $0,026 *$ \\
\hline $\begin{array}{l}\text { Comisión delitos para adquirir } \\
\text { Heroína }\end{array}$ & $\begin{array}{c}\text { Comisión delitos para adquirir } \\
\text { Cocaína }\end{array}$ & 0,501 & $0,000 * *$ \\
\hline $\begin{array}{l}\text { Delinquir bajo el Síndrome de } \\
\text { Abstinencia }\end{array}$ & Haber consumido Heroína & 0,428 & $0,000 * *$ \\
\hline Delincuencia $\rightarrow$ Drogadicción & Homicidio & 0,220 & $0,040 *$ \\
\hline
\end{tabular}




\section{Delincuencia Inducida}

Es la delincuencia debida a la intoxicación producida por la ingestión de sustancias psicoactivas, capaces de desinhibir o estimular ciertos comportamientos (Delgado Bueno S, 1999; Elzo J y otros, 1992;)

El delito actual lo cometieron en estado de intoxicación 47 sujetos, lo que representa el 53,4\% de la muestra (Grafico 1).

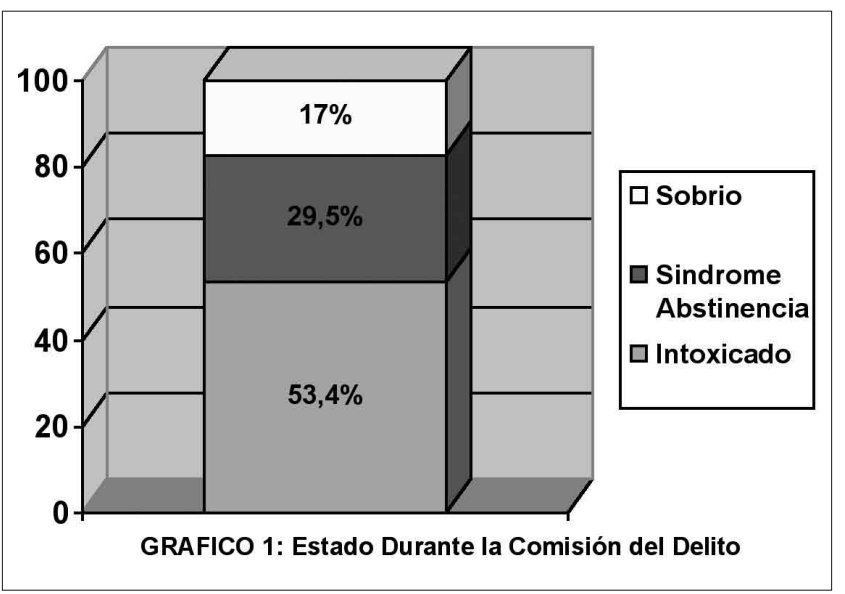

La/s sustancia/s que habían ingerido los que cometieron el delito en este estado fueron (Tabla 6):

\section{TABLA 6: Sustancias consumidas al realizar el delitos en estado de Intoxicación}

$\begin{array}{lc}\text { CANNABIS } & 7 \\ \text { HEROÍNA } & 21 \\ \text { COCAÍNA } & 38 \\ \text { ALCOHOL } & 14 \\ \text { BENZODIACEPINAS } & 21 \\ \text { ANFETAMINAS } & 4 \\ \text { OTRAS SUSTANCIAS } & 3\end{array}$

El 82,4\% habían consumido más de una sustancia al cometer el delito. Analizando los datos, aparece una correlación positiva entre haber consumido cocaína y haber consumido heroína previamente a la comisión del delito. ( $r=0,391$ significativo al nivel 0,000).

De los 21 sujetos que declaran haber consumido heroína cuando cometieron el delito en estado de intoxicación, el 100\% (los 21) habían consumido también cocaína.
Cuando cometen el delito en estado de intoxicación, lo más probable es que hayan consumido alguna de estas sustancias: Cocaína, Alcohol y Benzodiacepinas. Este dato queda corroborado por la correlación que existe entre cometer el delito intoxicado y dichas sustancias. Intoxicado por Cocaína ( $r=0,383$ significativa al nivel 0,000); Intoxicado por Alcohol ( $r=0,363$ significativa al nivel 0,001); Intoxicado por Benzodiacepinas ( $r=0,355$ significativa al nivel 0,001). (Tabla 7)

Los sujetos intoxicados por estas tres sustancias cometieron los siguientes delitos:

Cocaína: 4 homicidios, 11 robos con fuerza, 24 robos con intimidación, 9 delitos de lesiones, 3 atentados contra la autoridad, 1 delito contra la libertad.

Alcohol: 3 homicidios, 3 robos con fuerza , 6 robos con intimidación, 5 delitos de lesiones.

Benzodiacepinas: 2 homicidios, 9 robos con fuerza, 14 robos con intimidación, 3 delitos de lesiones, 3 atentados contra la autoridad, 1 delitos contra la libertad.

En cuanto a los delitos cometidos en estado de intoxicación aparece una correlación positiva entre estar intoxicado y cometer delitos de lesiones ( $r=$ 0,260 significativa al nivel 0,014) (Tabla 8).

Una correlación positiva entre estar intoxicado por el alcohol y delito de lesiones ( $r=0,237$ significativa al nivel 0,026) (Tabla 9).

Destacar el hecho de que el 65,9\% de los que delinquen intoxicados, cometieron el delito de robo con intimidación.

\section{Delincuencia Funcional}

Es la delincuencia realizada por un drogodependiente con la finalidad de conseguir los fondos necesarios para la adquisición de la droga (Delgado Bueno S, 1999; Elzo J y otros, 1992;).

Además de preguntar por el delito actual, se les preguntó si habían delinquido para conseguir dinero para conseguir droga:

El 88,6\% declara haber delinquido en alguna ocasión para conseguir dinero para poder comprar droga, de los que declararon esto, actualmente están en prisión por haber cometido principalmente los siguientes delitos:

- 23 de ellos cometieron robos con fuerza.

- 55 de ellos cometieron robos con intimidación.

Lo que parece muy claro es que la demanda económica que genera la drogadicción multiplica el número de delitos cometidos por los drogodependientes, el 88,6\% (78 sujetos) declaró que aumentó el número 
TABLA 7: Cometer el delito intoxicado $x$ consumo de sustancias

\begin{tabular}{|c|c|c|}
\hline $\begin{array}{c}\text { Número de sujetos que cometieron } \\
\text { el delito en estado de intoxicación: }\end{array}$ & $\begin{array}{c}\mathbf{N}^{\circ} \text { de sujetos que cometieron el } \\
\text { delito en estado de intoxicación } \\
\text { habiendo consumido: }\end{array}$ & $\begin{array}{c}\mathbf{N}^{\circ} \text { de sujetos que al cometer } \\
\text { el delito consumieron: }\end{array}$ \\
\hline 47 & $\begin{array}{c}\text { Cocaína: } 38 \\
\text { Alcohol: } 14\end{array}$ & $\begin{array}{c}\text { Cocaína: } 56 \\
\text { Alcohol: } 15\end{array}$ \\
Benzodiacepinas: 10 & Benzodiacepinas: 20 \\
\hline
\end{tabular}

TABLA 8: Cometer el delito en estado de intoxicación x cometer delito de lesiones

\begin{tabular}{|c|c|c|}
\hline $\begin{array}{c}\text { Número de sujetos que cometieron } \\
\text { el delito por el que están en prisión } \\
\text { en estado de intoxicación: }\end{array}$ & $\begin{array}{c}\mathbf{N}^{\circ} \text { de sujetos que cometieron el } \\
\text { delito de lesiones en estado de } \\
\text { intoxicación: }\end{array}$ & $\begin{array}{c}\mathbf{N}^{\circ} \text { de sujetos que cometieron } \\
\text { el delito de lesiones: }\end{array}$ \\
\hline 47 & 11 & 13 \\
\hline
\end{tabular}

TABLA 9: Cometer delitos intoxicado por alcohol x cometer delito de lesiones

\begin{tabular}{|c|c|c|}
\hline $\begin{array}{c}\text { Número de sujetos que cometieron } \\
\text { el delito por el que están en prisión } \\
\text { intoxicados por alcohol: }\end{array}$ & $\begin{array}{c}\mathbf{N}^{\circ} \text { de sujetos que cometieron el } \\
\text { delito de lesiones intoxicados } \\
\text { por alcohol: }\end{array}$ & $\begin{array}{c}\mathbf{N}^{\circ} \text { de sujetos que cometieron } \\
\text { el delito de lesiones: }\end{array}$ \\
\hline 15 & 5 & 13 \\
\hline
\end{tabular}

de delitos que realizaban cuando estaban enganchados.

Las drogas por las que generaban este desmedido aumento de la delincuencia fueron:

El 82,05\% (64 sujetos) de los que delinquían para adquirir droga, lo hacían para adquirir heroína.

El 94,87\% (74 sujetos) de los que delinquían para adquirir droga, lo hacían para adquirir cocaína.

Y reseñar el dato de que el 78,2\% (61sujetos) lo hacían para adquirir ambas sustancias.

Se ha encontrado una fuerte correlación entre cometer delitos para adquirir Heroína y cometer deli- tos para adquirir Cocaína ( $r=0,501$ significativa al nivel 0,000). (Tabla 10)

Relacionado con la delincuencia funcional, está la comisión de delitos bajo los efectos del síndrome de abstinencia de alguna sustancia. La inmensa mayoría de los delitos cometidos bajo el síndrome de abstinencia, se realizan con la finalidad de conseguir fondos para adquirir la droga.

26 sujetos (el 29,5\% de la muestra) cometieron el delito por el que actualmente están en prisión bajo los efectos del síndrome de abstinencia. La/s Sustancia/s que habían ingerido los que cometieron el delito en este estado fueron (Tabla 11):

Y cometieron:

TABLA 10: Cometer delitos para adquirir cocaína x cometer delitos para adquirir heroína

\begin{tabular}{|c|c|c|}
\hline $\begin{array}{c}\text { Número de sujetos que cometieron } \\
\text { delitos para adquirir Cocaína: }\end{array}$ & $\begin{array}{c}\mathbf{N}^{\circ} \text { de sujetos que cometieron } \\
\text { delitos para adquirir Cocaína } \\
\text { y Heroína: }\end{array}$ & $\begin{array}{c}\mathbf{N}^{\circ} \text { de sujetos que cometieron } \\
\text { delitos para adquirir } \\
\text { Heroína: }\end{array}$ \\
\hline 74 & 61 & 64 \\
\hline
\end{tabular}


TABLA 11: Sustancias consumidas al realizar el delito bajo el síndrome de Abstinencia

$\begin{array}{lc}\text { CANNABIS } & 1 \\ \text { HEROÍNA } & 21 \\ \text { COCAIINA } & 18 \\ \text { BENZODIACEPINAS } & 5 \\ \text { OTRAS SUSTANCIAS } & 3\end{array}$

- 7 robos con fuerza (en los 7 se había consumido cocaína y heroína).

- 21 robos con intimidación (15 habían consumido cocaína y 17 heroína).

- 2 delitos contra la libertad (Los dos habían consumido Cocaína y Heroína).

Se ha encontrado una correlación positiva entre haber cometido el delito bajo el síndrome de abstinencia y haber consumido heroína. $(r=0,428$ significativa al nivel 0,000) (Tabla 12).

Destacar el hecho de que el 80,77\% de los reclusos que cometieron el delito bajo el síndrome de abstinencia, cometieron el delito de robo con intimidación.

TABLA 12: Cometer el delito bajo el síndrome de abstinencia $x$ estar bajo los efectos de la heroína

\begin{tabular}{|c|c|c|}
\hline $\begin{array}{c}\text { Número de sujetos que cometieron } \\
\text { el delito por el que están en prisión } \\
\text { bajo el síndrome de abstinencia: }\end{array}$ & $\begin{array}{c}\mathbf{N}^{\circ} \text { de sujetos que cometieron el } \\
\text { delito bajo el síndrome de } \\
\text { abstinencia de la heroína: }\end{array}$ & $\begin{array}{c}\mathbf{N}^{\circ} \text { de sujetos que estaban bajo } \\
\text { los efectos o ausencia de la } \\
\text { heroína al cometer el delito: }\end{array}$ \\
\hline 26 & 21 & 42 \\
\hline
\end{tabular}

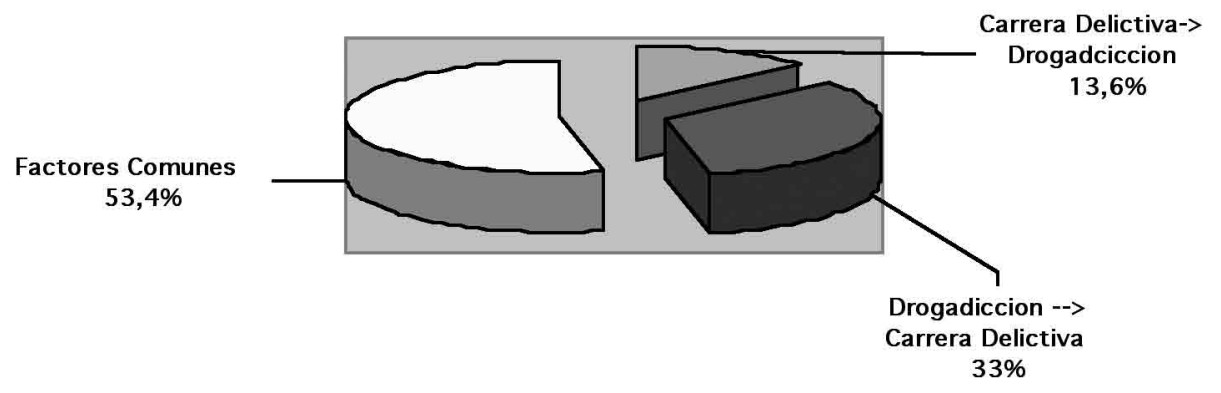

GRÁFICO 2: Direccionalidad de la Relación Droga-Crimen.

Al 33\% de la muestra (29 sujetos), la drogadicción les llevó a ser delincuentes.

Refieren que si no hubiese sido por la droga, nunca hubiesen cometido delitos.

Al 13, 6\% (12 sujetos) su carrera delictiva le llevó a la drogadicción, declaran que si no hubiesen come- tido delitos, no habrían llegado a ser drogadictos. Al realizar el análisis de las correlaciones entre variables, aparece una correlación entre los sujetos a los que la delincuencia les llevó a la drogadicción y el delito de homicidio y sus formas ( $r=0,220$ significativa al nivel 0,040) (Tabla 13).

\section{TABLA 13: Delincuencia lleva a la drogadicción $x$ cometer delito de homicidio}

\begin{tabular}{|c|c|c|}
\hline $\begin{array}{c}\text { Número de sujetos a los que la } \\
\text { delincuencia lleva a la drogadicción: }\end{array}$ & $\begin{array}{c}\mathbf{N}^{\circ} \text { de sujetos a los que la } \\
\text { delincuencia lleva a la drogadicción } \\
\text { que cometieron delito de homicidio: }\end{array}$ & $\begin{array}{c}\mathbf{N}^{\circ} \text { de sujetos que cometieron } \\
\text { delito de homicidio: }\end{array}$ \\
\hline 12 & 3 & 8 \\
\hline
\end{tabular}


El $53,4 \%$ de la muestra (47 sujetos) declara la existencia de factores comunes.

En el presente estudio, este grupo de sujetos en los que existen factores comunes a ambas entidades, el 51,06\% tienen familiares con problemas de consumo, el 42,55 \% veía consumir a familiares antes de iniciarse él en el consumo (drogas ilegales y consumo problemático de alcohol). El 40,42\% ha tenido familiares en prisión antes de que el ingresara y el $27,66 \%$ tiene actualmente algún familiar en prisión.

\section{Cifra Negra}

Como cifra negra entendemos los delitos realizados por los cuales la justicia no ha podido encontrar al responsable de su comisión.

El número de delitos totales (aunque no les hayan detenido), cometidos por los reclusos del estudio, da una cifra de 30269. Lo que significa que cometen una media de 343,96 delitos por persona.

Dada la enorme dificultad de calcular este dato, se hizo de forma aproximativa, sin más pretensión que tener una idea de la cifra negra de delitos. Cabe aclarar que la tendencia en el calculo fue el redondeo hacia abajo. Hay que tener en cuenta que muchos de los sujetos participantes son delincuentes con una extensa carrera delictiva, en los que en los momentos en los que estaban "enganchados", bastantes de ellos cometían delitos diarios, incluso varios robos al día. Para calcular este dato se dividió los delitos en intervalos de la siguiente forma (Tabla14):

\section{TABLA 14: Número de delitos realizados}

$$
\begin{gathered}
\text { Menos de } 10 \\
\text { Entre } 10 \text { y } 50 \\
\text { Entre } 50 \text { y } 100 \\
\text { Entre } 100 \text { y } 150 \\
\text { Entre } 150 \text { y } 200 \\
\text { Entre } 200 \text { y } 250 \\
\text { Entre } 250 \text { y } 300 \\
\text { Entre } 300 \text { y } 350 \\
\text { Entre } 350 \text { y } 400 \\
\text { Entre } 400 \text { y } 500 \\
\text { Entre } 500 \text { y } 750 \\
\text { Entre } 750 \text { y } 1000 \\
\text { Más de } 1000
\end{gathered}
$$

El número de delitos en que fueron detenidos, hayan entrado o no en prisión, asciende a 1206, lo que supone una media de 13,7 delitos por persona. Este dato fue mucho mas fácil de obtener que el número de delitos anteriormente comentado, ya que la mayoría de ellos lo recordaba perfectamente.

En base a los datos obtenidos el número de delitos cometidos por los drogodelincuentes es 25,09 veces superior al número de delitos en los que les detienen. $(30269 / 1206=25,09)$.

\section{DISCUSIÓN}

\section{Delincuencia Inducida}

A simple vista, los datos presentados pueden resultar extraños, ya que aparecen ciertas drogas bajo los efectos de las cuales supuestamente no suele cometerse delitos, como es el caso de la heroína, que es una droga que tiene como rasgo básico la atenuación de los impulsos agresivos, propiciando también sensación de tranquilidad, analgesia, apatía, disminución de la actividad física, etc. (Lorenzo P, 1998) En todo caso el heroinómano delinque bajo el síndrome de abstinencia, ya que la retirada de esta sustancia del organismo, produce irritabilidad y/u hostilidad.

Pero haciendo un análisis algo más exhaustivo, los datos obtenidos no contradicen el conocimiento científico que se posee de las distintas sustancias. Este contradictorio dato se explica debido al hecho de que la mayoría de los sujetos de la muestra (así como la mayoría de los drogodependientes) no son consumidores de una sola sustancia, sino que son policonsumidores.

Todo depende de la dosis. Mezclan sustancias para compensar unos efectos, y/o potenciar otros. Y en estos reclusos, seguramente primaba el efecto de la cocaína sobre el de la heroína.

De los 7 que habían consumido Cannabis, 5 habían consumido además Cocaína, 4 alcohol, 2 anfetaminas, entre otras sustancias más.

De los 14 que habían tomado alcohol , 11 habían consumido también Cocaína, y diversas sustancias más.

\section{Delincuencia Funcional}

Esta delincuencia está determinada principalmente por dos factores: 
El grado de dependencia física / psíquica a la droga.

La capacidad para sufragarla por vías no delictivas (a su vez determinada en función de si la propia delincuencia le permite llevar a cabo una vida laboral y del precio de la sustancia de la que es dependiente).

La drogodependencia favorece la comisión de actos delictivos debido a la demanda económica que genera.

Lo que parece muy claro es que la demanda económica que genera la drogadicción multiplica el número de delitos cometidos por los drogodependientes, como ya se mencionó, el 88,6\% (78 sujetos) declaró que aumentó el número de delitos que realizaban cuando estaban enganchados.

Las drogas por las que generaban este desmedido aumento de la delincuencia fueron: heroína y cocaína.

Confirmándose lo expuesto anteriormente, este tipo de delincuencia es característica de los sujetos con una dependencia a las drogas ilegales debido a su alto precio, el alto y pronto grado de dependencia física y psíquica que estas sustancias suelen producir.

Como comentaba anteriormente relacionado con la delincuencia funcional, está la comisión de delitos bajo los efectos del síndrome de abstinencia de alguna sustancia. Casi todos los delitos cometidos bajo el síndrome de abstinencia, se realizan con el objetivo de conseguir fondos para adquirir la droga. Típica es la imagen del heroinómano, que delinque bajo el síndrome de abstinencia para poder drogarse nuevamente, y así acabar con el malestar generado por la ausencia de la droga en su organismo.

\section{Dirección de la Relación Droga Crimen}

La literatura científica apunta tres posibilidades en esta relación:

La primera es que la droga lleva a la delincuencia. (Delgado Bueno S, 1999; Kaiser G, 1998; Marquez Cervilla A, 1990; Otero Lopez JM, 1999).

Por un lado cabe la posibilidad de que una vez que el sujeto ha caído en la adicción a una sustancia, no sea capaz de sufragarla por medios no delictivos. Hay que tener en cuenta que drogas ilegales, como la cocaína o la heroína, tienen un alto precio y generan en poco tiempo una alta dependencia física y psíquica, lo que a su vez puede llevar a no poder compatibilizar el consumo de dichas sustancias con una vida sociolaboral más o menos normal, lo que hará aún mayor la distancia entre capacidad económica del sujeto y la posibilidad de adquirirla por vías no delictivas. (Harrison L, 2000).
Por otro lado, también cabe la posibilidad de que el sujeto se exima de su responsabilidad, culpabilizando de su situación a "la droga".

La segunda posibilidad recogida en la literatura, es que la delincuencia lleva a la drogadicción. (Delgado Bueno S, 1999; Kaiser G, 1998; Marquez Cervilla A, 1990; Otero Lopez JM, 1999).

Desde esta visión se propugna que los drogodelincuentes están implicados con anterioridad en la delincuencia, y que la adicción a la droga no es más que una prolongación de la conducta ya criminal.

Y la tercera hipótesis es la existencia de determinantes comunes. (Delgado Bueno S, 1999; Kaiser G, 1998; Marquez Cervilla A, 1990; Otero Lopez JM, 1999).

Delincuencia y consumo de sustancias, son parte de un estilo de vida desviado cuyo origen hay que buscarlo en una serie de factores interrelacionados y cualquier asociación puede ser incidental. Los defensores de esta hipótesis apuntan que drogadicción y delincuencia son el resultado de una serie de factores comunes, y ambas conductas pueden surgir indistintamente o conjuntamente.

Algunos factores relacionados entre delincuencia y drogas pueden ser (Delgado Bueno S, 1999; Mateos PM, 1988; Santo Domingo J, 2002; Vega Fuente A, 1990):

- Factores sociofamiliares: pobreza, inestabilidad laboral, ambiente familiar adverso, consumo por parte de sus padres, maltrato infantil...

- Factores sociológicos

- Factores individuales: hereditarios, alteraciones cromosómicas...

- Características individuales: agresividad, egocentrismo, labilidad emocional... patrón de personalidad de búsqueda de sensaciones.

Como se comentaba anteriormente, lo que si parece claro es que, independientemente de que llevó a qué, al introducirse el factor droga, el número de delitos aumenta.

\section{CONCLUSIONES}

A diferencia de los datos obtenidos en otras investigaciones, en los cuales se observa una mayor incidencia de la delincuencia funcional frente a la delincuencia inducida (Elzo J, Lindón JM, Urquijo ML, 1992 y Marquez Cervilla A, 1990), los datos obtenidos en nuestra investigación reflejan que la mayoría de los drogodelincuentes comenten delitos bajo la delin- 
cuencia inducida, se cometen más delitos en estado de intoxicación que bajo el síndrome de abstinencia.

Otro punto relevante de los datos obtenidos gira entorno a la causalidad en el binomio drogadicción - delincuencia, , difiriendo de otras investigaciones en las que es la delincuencia la que lleva a la drogadicción (Marquez Cervilla A, 1990). En nuestro estudio hallamos que la mayoría de los sujetos estudiados presentan una serie de factores comunes en la génesis de ambas entidades.

Habría que seguir observando los cambios que se siguen produciendo en la sociedad, ya que por ejemplo, con el fenómeno de la inmigración, es posible que se exporten nuevas formas de consumo, nuevas sustancias de las que abusar e incluso puede haber un rebrote de alguna de las sustancias cuyo consumo en España estaba más o menos controlado.

\section{REFERENCIAS}

American Psychiatric Association. (1995). Manual Diagnóstico y Estadístico de los Trastornos Mentales. DSM-IV. Barcelona: Masson.

Código Penal. (2000). Madrid: Tecnos.

Delgado, S., Torrecilla, J.M. (1999). Medicina Legal en Drogodependencias. Madrid: Agencia Antidroga de la Comunidad de Madrid.

Elzo J., Lidón, J.M., Urquijo, M.L. (1992). Análisis jurídico y sociológico de sentencias emitidas en las Audiencias Provinciales y en los Juzgados de la C.A.V. Delincuencia y Drogas. Vitoria-Gasteiz: Secretaria de la presidencia del Gobierno Vasco.
Garrido, V., Stangeland, P., Redondo, S. (1999). Principios de Criminología. Valencia: Tirant Lo Blanch.

Harrison, L. (2000). La Conexión Drogas-Violencia entre los adolescentes. En: Recio, J.L., Rodríguez, O. (Eds.), Conducta Antisocial, Violencia y Drogas en la Escuela (pp. 43-61). Madrid: Agencia Antidroga de la Comunidad de Madrid.

Kaiser, G. (1998). Introducción a la Criminología. Madrid: Dykinson.

Lorenzo, P., Ladero, J.M., Leza, J.C., Lizasoain, I.. (1998). Drogodependencias: Farmacología. Patología. Psicología. Legislación. Madrid: Panamericana.

Mateos, P.M., Prieto, G. (1988). La Drogadicción: Un Factor de Predisposición a la delincuencia. En: // Congreso Mundial Vasco: Congreso de Drogodependencias Análisis Multidisciplinar. (Tomo III, pp. 121-125).VitoriaGasteiz: Servicio central de Publicaciones del Gobierno Vasco.

Marquez, A. (1990). Drogadicción y Delincuencia. Revista de Estudios Penitenciarios, 243, 21-31.

Observatorio Español Sobre Drogas. (2002). Informe No 5 . Madrid: Delegación del Gobierno para el Plan Nacional sobre Drogas.

Otero, J.M. (1999). Relación droga-delincuencia en los adolescentes: una perspectiva de futuro desde una mirada al pasado.En: / Congreso Virtual sobre Drogodependencias. Recuperado el 11 de Agosto de 2003 de http:// www.fad.es/estudios/congreso_virtual.html.

Santo-Domingo, J. (2002, febrero). El desarrollo Personal del Joven y el Alcohol. Comunicación presentada al Congreso Sobre Jóvenes Noche y Alcohol, Madrid.

Vega, A. (1990). Delincuencia y Drogas: Reflexiones Pedagógicas. Delincuencia, 2 (3), 247-271. 


\section{SOCIDROGALCOHOL}

\section{SOLICITUD DE INSCRIPCIÓN COMO SOCIO}

Nombre y dos apellidos

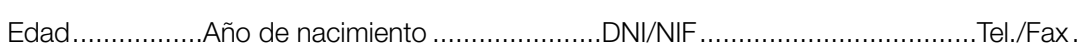

Domicilio

C.P.

Ciudad y Provincia

Profesión

..Cargo

Centro de trabajo y dirección

Socios que avalan su inscripción (dos).

Nombre Firma:

Nombre Firma:

En, a

de de

El solicitante, (Firma)

Sr. Director de,

BANCO o CAJA DE AHORROS

..Sucursal .

Dirección.

C.P.......

Ciudad

..Teléfono

Ruego a Uds. que hasta nuevo aviso se sirvan atender con cargo a mi Cuenta Corriente/libreta de ahorro $\mathrm{n}^{\circ}$....... Entidad

Oficina ….......................C. .los recibos que a mi nombre le sean presentados por,

\section{SOCIDROGALCOHOL}

Les saluda atentamente, (Firma)

En, a de de

A. SOCIDROGALCOHOL. Sírvanse tomar nota que doy orden a

BANCO O CAJA DE AHORROS

Sucursal....... ...Dirección

C.P. Ciudad para que sean atendidos con cargo a

mi, C/C o Llbreta $n^{\circ}$ ..Entidad .Oficina ..D.C.

los recibos que por Cuota de Asociados a SOCIDROGALCOHOL (C.I.F. G58333420), me sean presentados por esa Asociación. En a. de de. (Firma)

Nombre

Domicilio

C.P.

NOTA: Enviar este impreso íntegro a la Presidencia de SOCIDROGALCOHOL, quien tras tomar los datos oportunos remitirán al Banco o Caja de Ahorros que proceda, la parte superior del mismo. iGRACIAS!

SOCIDROGALCOHOL. Vía Augusta, 229 bajos. 08021 BARCELONA. Tel. 9717274 34. Fax: 971213306 • E-mail: secretaria.adicciones@eurociber.es 